\title{
Consensus on paramedic clinical decisions during high-acuity emergency calls: results of a Canadian Delphi study
}

\author{
Jan L. Jensen, ACP MAHSR**; Pat Croskerry, PhD, MD ${ }^{\ddagger \S}$; Andrew H. Travers, MD, MSc ${ }^{\dagger \ddagger \S}$

\section{ABSTRACT}

\section{RÉSUMÉ}

Objectives: To establish consensus on the most important clinical decisions paramedics make during high-acuity emergency calls and to visualize these decisions on a process map of an emergency call. A secondary objective was to measure agreement among paramedics and medical director panel members.

Methods: A multiround online survey of Canadian paramedics and medical directors. In round 1, participants listed important clinical decisions. In round 2, participants scored each decision in terms of its importance for patient outcome and safety. In rounds 3 and 4, participants could revise their scores. Consensus was defined a priori: $80 \%$ or more agreement that a decision was important or extremely important. The included decisions were plotted on a process map of a typical emergency call.

Results: The panel response rates were as follows: round 1 , $96 \%$; round 2, 92\%; round 3, $83 \%$; and round 4, $96 \%$. Consensus was reached on 42 decisions, grouped into six categories: airway management $(n=13)$; assessment $(n=$ $3)$; cardiac management $(n=7)$; drug administration $(n=9)$; scene management $(n=4)$; and general treatment $(n=6)$. The on-scene treatment phase of the process map was found to have the highest decision density. Paramedics and medical directors differed in their scoring in 5 of 42 decisions ( $p<0.05$ or less).

Conclusion: Consensus was reached among paramedics and medical directors on 42 decisions important for clinical outcome and patient safety. These decisions were visualized on a process map of an emergency call to learn more about where decision density exists during a typical call.
Objectifs : Établir un consensus sur les décisions cliniques les plus importantes que les ambulanciers ont à prendre lors des appels d'urgence de gravité élevée et illustrer ces décisions sur un diagramme du processus de l'appel d'urgence. Un objectif secondaire était de mesurer l'accord entre les ambulanciers et les membres du groupe de directeurs médicaux.

Méthodes : Sondage échelonné, effectué en ligne par les ambulanciers et directeurs médicaux canadiens. Pendant le cycle 1, les participants ont établi la liste des décisions cliniques importantes. Au cycle 2, les participants ont accordé une note à chaque décision en ce qui a trait à son importance pour les résultats et la sécurité du patient. Aux cycles 3 et 4, les participants pouvaient réviser leurs notes. Le consensus a été défini a priori: I'accord à $80 \%$ ou plus sur le fait qu'une décision était importante ou extrêmement importante. Les décisions incluses étaient inscrites sur le diagramme du processus d'un appel d'urgence typique.

Résultats : Les taux de réponse du panel étaient les suivantes: cycle 1,96\%; cycle 2, 92\%; cycle 3, $83 \%$; cycle 4, $96 \%$. Un consensus a été atteint pour 42 décisions, regroupées en six catégories: gestion des voies respiratoires ( $n=13)$; évaluation $(n=3)$; gestion cardiaque $(n=7)$; administration de médicaments $(n=9)$; gestion des lieux ( $n=4)$ et traitement général $(n=6)$. La phase de traitement sur les lieux du diagramme du processus comportait la plus grande densité de décision. Les ambulanciers et les directeurs médicaux différaient dans leurs scores pour 5 des 42 décisions (p 0,05 ou moins).

Conclusion : Un consensus a été trouvé entre les ambulanciers et les directeurs médicaux pour 42 décisions importantes liées aux résultats et à la sécurité du patient. Ces

From the *Division of Emergency Medical Services, Dalhousie University, Halifax, NS; †Emergency Health Services, Dartmouth, NS; $¥ D e p a r t m e n t$ of Emergency Medicine, Dalhousie University, Halifax, NS; §Capital District Health Authority, Halifax, NS.

Presented at the Canadian Association of Emergency Physicians Annual Scientific Assembly, Montreal, QC, May 31-June 3, 2010.

Correspondence to: Jan L. Jensen, Division of Emergency Medical Services, Dalhousie University, QEII Health Sciences Centre, 1796 Summer Street, Room 3022, Halifax, NS B3H 3A7; jljensen@dal.ca.

Submitted July 27, 2010; Revised October 14, 2010; Accepted October 24, 2010.

This article has been peer reviewed. 
décisions ont été inscrites sur un diagramme du processus d'appel d'urgence pour nous informer davantage sur la présence de densité décisionnelle pendant un appel typique.
Keywords: decision making, Delphi, emergency medical services, paramedics
Clinical decision making (CDM) by health care professionals is related to patient safety and clinical outcomes. ${ }^{1}$ Decision making, together with skill performance, system design, and medication errors, is linked to adverse events. O'Connor and colleagues published a review of errors in emergency medical services (EMS) and discussed some of the more easily identified sources of error. ${ }^{2}$ They included medication administration, endotracheal intubation, and nontransport. Although this article briefly discussed the potential impact of paramedic cognition on error rates, it did not establish how to improve paramedic CDM. Studies have been conducted on paramedic errors during specific interventions, such as airway management, ${ }^{3}$ and for general paramedic practice. ${ }^{4}$ Relatively little research has been conducted on decisions made by paramedics during high-acuity emergency calls. ${ }^{5}$ In an ethnographic study exploring errors, adverse events, and near misses in EMS, the predominant factor was found to be paramedic decision making. ${ }^{6}$ This finding was similar to that of a recent qualitative Canadian study in which EMS experts identified CDM as one of two predominant themes influencing patient safety in EMS.?

During a typical emergency call, paramedics may be presented with a wide spectrum of clinical complaints, scene complexities, and assessment and management demands. Because paramedic cognition is thought to be a factor influencing patient safety and likely clinical outcomes, to best determine how to minimize the chance of adverse events and errors, it is first necessary to identify which clinical decisions paramedics make that are likely to have the greatest impact.

The objectives of this study were to achieve consensus among a group of Canadian EMS experts on the most important decisions paramedics make during typical high-acuity emergency calls in terms of clinical outcome and patient safety; to visualize these decisions on a process map of an emergency call; and to determine the degree of consensus among the two participant subgroups (paramedics and EMS medical directors).

\section{METHODS}

\section{Sample and setting}

A sample of paramedics and EMS medical directors from across Canada was recruited through two national associations (the EMS Chiefs of Canada and the Canadian Association of Emergency Physicians EMS Committee). E-mails advertising the study opportunity were sent out through group contact lists. Requirements for participation included the following: paramedics had to be advanced care paramedics or have a higher level of training, and medical directors had to directly oversee paramedic clinical practice or be regional or provincial EMS medical directors. Participants were informed that their identity would remain anonymous, and all signed consent forms prior to the start of the study. This study received approval from the Capital District Health Authority Research Ethics Board in Halifax, Nova Scotia (\#CDHA-RS/ 2009-113).

\section{Methods of measurement}

An online survey tool was used to deliver the surveys. ${ }^{8}$ Each round of the Delphi study was open for 2 weeks. In the first round, participants entered clinical decisions (i.e., decisions made by paramedics in regard to assessment, treatment, or transport) they felt were important during a high-acuity emergency call in a free-text box. The responses were sorted into a list, maintaining the original wording of the respondent as much as possible. ${ }^{9,10}$ Duplicate decisions were removed from the list. In the second round of the survey, panelists scored the importance of each decision on a Likert scale: 1 = not important, very unlikely to impact patient clinical outcome or patient safety; 2 = not very important, unlikely to impact patient clinical outcome or patient safety; 3 = possibly important, may impact patient clinical outcome or patient safety; $4=$ important; in most instances, these decisions will impact patient clinical outcome or patient safety; $5=$ 
extremely important, very likely that these decisions will impact patient clinical outcome or patient safety. Consensus on "important" was defined a priori if $80 \%$ of the panel scored a decision as 4 ("important") or 5 ("extremely important"). Decisions that achieved panel consensus in round 2 were removed from the list for round 3, and the same process was followed for round 4. In rounds 2 and 3, participants were asked to add any new decisions they thought of and provide free-text comments. In rounds 3 and 4, participants viewed their own scores for each decision, as well as the panel mean score for each decision. Participants could change their scores from the previous round on any decision in light of the panel mean. It was decided a priori that the study would conclude after a maximum of four rounds to avoid sample fatigue. ${ }^{11}$

\section{Data analysis}

Data were downloaded from the survey tool into a Microsoft Excel spreadsheet (Microsoft Corp., Redwood, CA), in which descriptive analysis of panel characteristics, categorization of free text, and preliminary analysis (mean scores and level of consensus) of each decision in each round were conducted. Scores for included decisions were entered into the statistical software program SPSS 15.0 (SPSS Inc, Chicago, IL). Independent sample $t$-tests were conducted to determine differences in paramedic and medical director scoring for each included decision and for each decision category. Significance was set at $p<0.05$.

The final important paramedic decisions were plotted onto a process map, ${ }^{12}$ in the order of when they would likely arise during a typical emergency call. The investigators came to consensus about the plotting of each decision. The purpose of the process map is to diagram when paramedics make important decisions during emergency calls to learn more about when the highest decision densities are likely to occur.

The methods for this study have been previously described in detail. ${ }^{13}$

\section{RESULTS}

The panel consisted of 24 participants from across Canada, with a mean 16.5 years of experience (range 340 years). There were seven medical directors and 17 paramedics, the latter of whom worked a variety of roles: ground ambulance paramedic, supervisor or manager, quality assurance, clinical development, and educator. The majority of panel members were from Ontario (Table 1). The panel response rate was excellent for all rounds of the study: round 1,96\%; round 2, 92\%; round 3, 83\%; and round 4, 96\%.

Forty-two clinical decisions were determined to be important. Consensus was achieved for 19 decisions in round 2 (Table 2), 18 decisions in round 3 (Table 3), and 5 decisions in round 4 (Table 4). Clinical decisions were sorted into the following decision categories by one of the authors (J.L.J.): airway management $(n=$ $13)$; assessment $(n=3)$; cardiac management $(n=7)$; drug administration $(n=9)$; general treatment $(n=6)$; and scene management $(n=4)$. The categories with the highest mean scores were airway management and cardiac management (both 4.49) (Table 5). The category with the highest consensus among the panel was assessment $(97 \%$ of panel scored items in this category as 4 or 5 ).

Paramedics scored four decisions higher than medical directors: decide on airway device $(p<0.05)$;

\begin{tabular}{|c|c|c|c|}
\hline Primary Employment Role & & $n$ & \\
\hline Panel members & & 24 & \\
\hline Paramedics & & 17 & \\
\hline Ground ambulance & & 3 & \\
\hline Supervisor/management & & 2 & \\
\hline Quality assurance & & 4 & \\
\hline Clinical development & & 5 & \\
\hline Educator & & 3 & \\
\hline Medical directors & & 7 & \\
\hline Direct oversight & & 3 & \\
\hline Regional/provincial & & 4 & \\
\hline Experience & Mean (yr) & $\begin{array}{l}\text { Minimum } \\
(y r)\end{array}$ & $\begin{array}{l}\text { Maximum } \\
(y r)\end{array}$ \\
\hline Panel & 16.53 & 3 & 40 \\
\hline Paramedics & 20.15 & 3 & 40 \\
\hline Medical directors & 10.62 & 4 & 18 \\
\hline Province & Panel & Paramedics & $\begin{array}{l}\text { Medical } \\
\text { directors }\end{array}$ \\
\hline Alberta & 3 & 3 & - \\
\hline British Columbia & 2 & 1 & 1 \\
\hline Manitoba & 3 & 2 & 1 \\
\hline Nova Scotia & 1 & - & 1 \\
\hline Ontario & 13 & 9 & 4 \\
\hline Saskatchewan & 2 & 2 & - \\
\hline
\end{tabular}




\begin{tabular}{|c|c|c|c|c|}
\hline \multirow[b]{2}{*}{ Decision } & \multirow[b]{2}{*}{ Consensus (\%) } & \multicolumn{3}{|c|}{ Mean } \\
\hline & & Panel & Paramedic & MD \\
\hline Recognize signs of life-threatening trauma & 100 & 4.59 & 4.60 & 4.57 \\
\hline Decide how to confirm intubation & 95 & 4.58 & 4.46 & 4.85 \\
\hline Decide whether to perform cricothyrotomy & 95 & 4.95 & 4.93 & 5.00 \\
\hline $\begin{array}{l}\text { Decide to perform chest needle } \\
\text { decompression** }\end{array}$ & 95 & 4.85 & 5.00 & 4.50 \\
\hline $\begin{array}{l}\text { Begin chest compressions on decompensated } \\
\text { child (shock)* }\end{array}$ & 95 & 4.51 & 4.67 & 4.17 \\
\hline $\begin{array}{l}\text { Decide whether to attempt intubation in major } \\
\text { trauma patient }\end{array}$ & 91 & 4.44 & 4.38 & 4.57 \\
\hline Decision to defibrillate & 91 & 4.95 & 5.00 & 4.83 \\
\hline Start CPR & 91 & 4.85 & 4.87 & 4.80 \\
\hline Interpreting 12-lead ECG & 91 & 4.46 & 4.40 & 4.60 \\
\hline $\begin{array}{l}\text { Decide to use supraglottic device (King LT, } \\
\text { Combitube, LMA), ETI, or BMV** }\end{array}$ & 86 & 4.21 & 4.31 & 4.00 \\
\hline $\begin{array}{l}\text { Provide positive pressure ventilation with BVM } \\
\text { in respiratory distress }\end{array}$ & 86 & 4.46 & 4.42 & 4.57 \\
\hline $\begin{array}{l}\text { Failed attempt at intubation; try again for ETI or } \\
\text { switch to supraglottic device or BVM }\end{array}$ & 86 & 4.42 & 4.31 & 4.67 \\
\hline Give epinephrine for anaphylaxis* & 86 & 4.79 & 4.71 & 5.00 \\
\hline Decide to give TNK for STEMI & 86 & 4.58 & 4.58 & 4.57 \\
\hline Decide to use CPAP & 82 & 4.39 & 4.42 & 4.33 \\
\hline Provide ASA & 82 & 4.45 & 4.43 & 4.50 \\
\hline Provide bronchodilators & 82 & 4.32 & 4.36 & 4.25 \\
\hline $\begin{array}{l}\text { Decide when to leave scene v. manage/ } \\
\text { treatment on scene (load and go v. stay and } \\
\text { play)* }\end{array}$ & 82 & 4.27 & 4.38 & 4.00 \\
\hline $\begin{array}{l}\text { Decide most appropriate destination (trauma, } \\
\text { heart, stroke centre, community ED, other) }\end{array}$ & 82 & 4.40 & 4.50 & 4.17 \\
\hline
\end{tabular}

perform chest decompression $(p<0.01)$; begin chest compressions on a decompensated child $(p<0.05)$; and decide when to leave the scene versus stay $(p<$ 0.05). Medical directors scored one decision higher than paramedics: give epinephrine for anaphylaxis $(p<$ $0.05)$. No differences were found in paramedic or medical director mean scores for each decision category (see Table 5).

The included decisions were plotted on a process map of an emergency call (Figure 1, Table 6). Visualization of this map shows that the majority of decisions that have implications for clinical outcome and safety occur during the on-scene treatment phase. Decisions in the airway management, cardiac management, and drug administration categories predominate this phase of the process map.

\section{DISCUSSION}

Identifying areas of importance can have a direct impact on paramedic training and patient outcomes. Recognition that airway management, cardiac management, drug administration, and assessment decisions categories were considered most important in terms of patient safety and clinical outcome should impact the focus of paramedic teaching and metacognition. Paramedics, especially those practicing at an advanced level, should be aware of the decisions found to be important for patient safety and outcome and the time period during a typical call when they can expect to make most of these decisions. Clinical evaluations and training sessions should include scenarios that include these findings to increase the 
Table 3. Clinical decisions: consensus achieved in round 3 (20 respondents, $n=18 \mathrm{CDM}$ items)

\begin{tabular}{|c|c|c|c|c|}
\hline \multirow[b]{2}{*}{ Decisions } & \multirow[b]{2}{*}{ Consensus (\%) } & \multicolumn{3}{|c|}{ Mean } \\
\hline & & Panel & Paramedic & MD \\
\hline Give epinephrine for severe asthma & 100 & 4.35 & 4.43 & 4.17 \\
\hline Decide to extubate if unsure of placement & 100 & 4.50 & 4.57 & 4.33 \\
\hline Decide on appropriate treatment & 95 & 4.58 & 4.54 & 4.67 \\
\hline Recognize contraindications/reason to withhold therapy & 95 & 4.63 & 4.64 & 4.60 \\
\hline $\begin{array}{l}\text { Decision to change care plan (switch protocol/medical directive) based } \\
\text { on patient changes }\end{array}$ & 95 & 4.16 & 4.14 & 4.20 \\
\hline Decide if patient has capacity to refuse or consent & 95 & 4.37 & 4.31 & 4.50 \\
\hline $\begin{array}{l}\text { Initial assessment: is patient critical; level of distress/acuity, decide } \\
\text { whether to start treatment right away, or complete assessment }\end{array}$ & 95 & 4.47 & 4.38 & 4.67 \\
\hline Decide to use drugs to facilitate intubation (sedation, opiates, paralytics) & 90 & 4.27 & 4.17 & 4.50 \\
\hline How to clear obstructed airway (Heimlich manoeuvre, suction, forceps) & 90 & 4.82 & 4.92 & 4.60 \\
\hline $\begin{array}{l}\text { Determine if patient requires immediate treatment or can wait until en } \\
\text { route, arrival at ED }\end{array}$ & 90 & 4.39 & 4.38 & 4.40 \\
\hline Give epinephrine for pediatric shock & 90 & 4.33 & 4.38 & 4.20 \\
\hline $\begin{array}{l}\text { Remind/correct chest compressor on CPR quality; have chest } \\
\text { compressors switch }\end{array}$ & 90 & 4.22 & 4.23 & 4.20 \\
\hline $\begin{array}{l}\text { Decide on manual airway positioning-if necessary and how (e.g., head } \\
\text { tilt, jaw thrust) }\end{array}$ & 85 & 4.18 & 4.15 & 4.25 \\
\hline $\begin{array}{l}\text { Reassess patient after giving a treatment; decision on next action (e.g., } \\
\text { stop drug, change, give another dose) }\end{array}$ & 85 & 4.34 & 4.38 & 4.25 \\
\hline Decide on drug for tachycardia (amiodarone/lidocaine/adenosine) & 85 & 4.11 & 4.15 & 4.00 \\
\hline Decide to check for/triage patients at scene with several patients & 85 & 4.11 & 4.15 & 4.00 \\
\hline Analyze cardiac rhythm (3- or 4-lead strip) & 80 & 4.12 & 4.09 & 4.20 \\
\hline $\begin{array}{l}\text { Recognize potential hazards (e.g., people, animals, environment, } \\
\text { chemical/radiologic/biologic risks); scene safety }\end{array}$ & 80 & 4.31 & 4.27 & 4.40 \\
\hline
\end{tabular}

ecologic validity of scenarios to portray real-time $\mathrm{CDM}$ demands ${ }^{14}$ (i.e., the learner is required to make many decisions during the on-scene treatment phase, and scenarios should include decisions found to be important in this study). Paramedics and medical directors who work in EMS continuous quality improvement should be aware of these findings and seek ways to improve paramedic CDM in their service, such as providing paramedics with effective and novel resources during the on-scene treatment phase, including quick access to medical control and quick reference guides.

Interestingly, paramedics and medical directors differed on their scoring on only 5 of the included 42 decisions, which justifies this method of interprofessional consensus building. The paramedics who

\begin{tabular}{|c|c|c|c|c|}
\hline \multirow[b]{2}{*}{ Decision } & \multirow[b]{2}{*}{ Consensus (\%) } & \multicolumn{3}{|c|}{ Mean } \\
\hline & & Panel & Paramedic & MD \\
\hline $\begin{array}{l}\text { Decide whether to attempt intubation in pediatric } \\
\text { patient }\end{array}$ & 91 & 4.29 & 4.23 & 4.43 \\
\hline Decide to insert airway adjuncts (OPA, NPA) & 82 & 4.11 & 4.08 & 4.20 \\
\hline Decide whether to administer vasopressor & 82 & 4.00 & 4.00 & 4.00 \\
\hline $\begin{array}{l}\text { Decide on electrical cardioversion or medications } \\
\text { for SVT }\end{array}$ & 82 & 4.10 & 4.14 & 4.00 \\
\hline Decide how to manage labour and delivery & 82 & 4.00 & 4.00 & 4.00 \\
\hline
\end{tabular}




\begin{tabular}{|lcccc|}
\hline Table 5. Decision categories & \multicolumn{3}{c|}{ Mean } \\
\hline Decision category & $\begin{array}{c}\text { Number of } \\
\text { decisions }\end{array}$ & Panel & Paramedic & MD \\
\cline { 3 - 6 } Airway management & 13 & 4.49 & 4.49 & 4.49 \\
Assessment & 3 & 4.48 & 4.43 & 4.58 \\
Cardiac management & 7 & 4.49 & 4.51 & 4.44 \\
Drug administration & 9 & 4.36 & 4.36 & 4.35 \\
General treatment decisions & 6 & 4.42 & 4.42 & 4.42 \\
Scene management & 4 & 4.27 & 4.33 & 4.14 \\
\hline MD $=$ medical director. & & & & \\
\hline
\end{tabular}

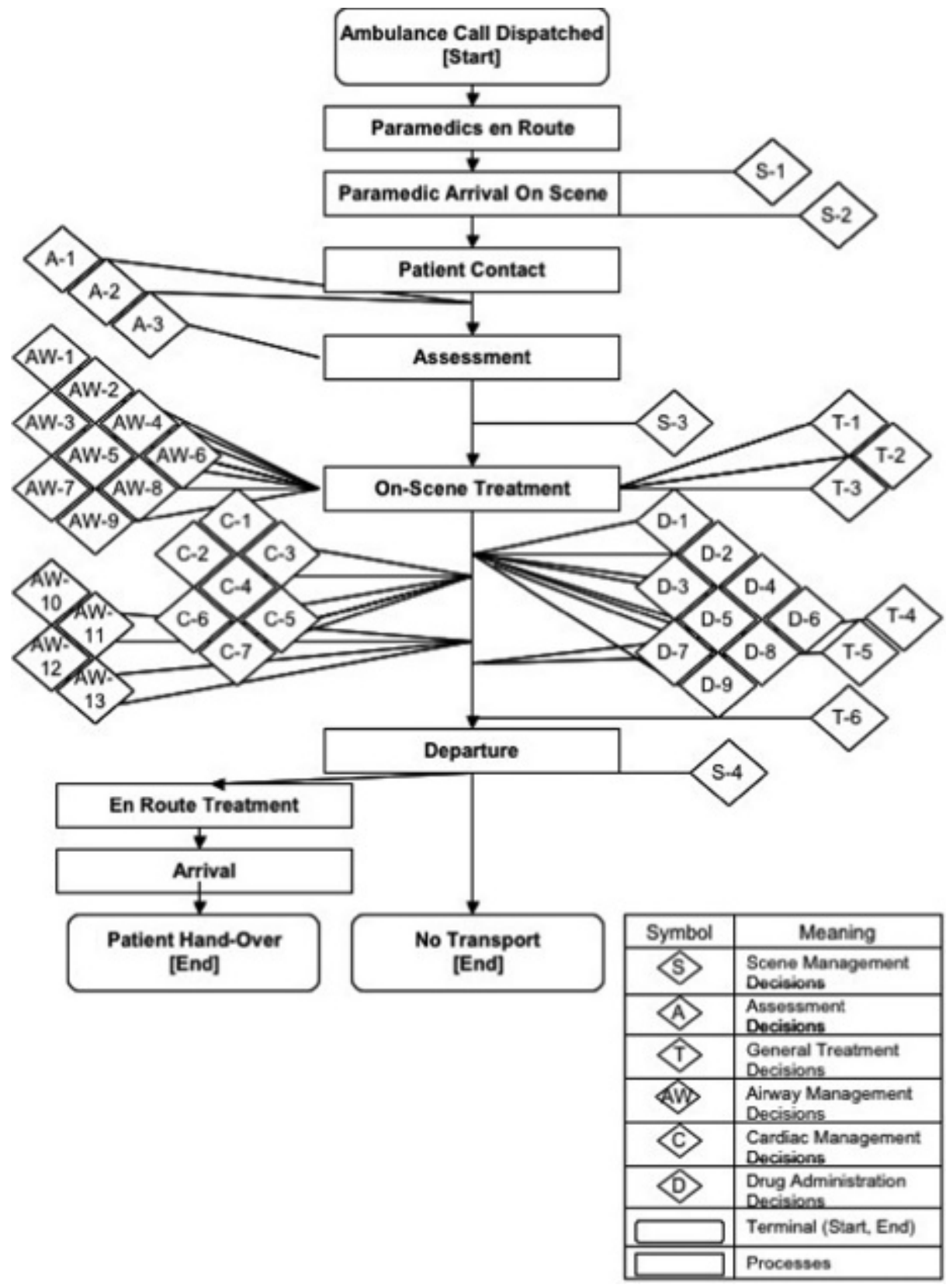

Figure 1. Process map. 
Table 6. Included decisions, in order on process map

Code Decision

S-1 Recognize potential hazards (e.g., people, animals, environment, chemical/radiologic/ biologic risks); scene safety

S-2 Decide to check for/triage patients at scene with several patients

A-1 Initial assessment: is patient critical; level of distress/acuity, decide whether to start treatment right away, or complete assessment

A-2 Recognize signs of life-threatening trauma

A-3

S-3

$\mathrm{T}-1$

$\mathrm{T}-2$

T-3

$\mathrm{T}-4$

Decide if patient has capacity to refuse or consent

Decide when to leave scene v. manage/treat on scene (load and go v. stay and play)

Decide on appropriate treatment

Determine if patient requires immediate treatment or can wait until en route, arrival at ED Recognize contraindications/reason to withhold therapy

Reassess patient after giving a treatment; decision on next action (e.g., stop drug, change, give another dose)

T-5 Decision to change care plan (switch protocol/medical directive) based on patient changes

T-6

D-1

D-2

D-3

D-4

D-5

D-6

D-7

D-8

D-9

AW-1

AW-2

AW-3

AW-4

AW-5

Decide how to manage labour and delivery

Provide ASA

Give epinephrine for anaphylaxis

Give epinephrine for severe asthma

Give epinephrine for pediatric shock

Decide to give TNK for STEMI

Provide bronchodilators

Decide to use drugs to facilitate intubation (sedation, opiates, paralytics)

Decide on drug for tachycardia (amiodarone/lidocaine/adenosine)

Decide whether to administer vasopressor

Decide on manual airway positioning -if necessary and how (e.g., head tilt, jaw thrust) Decide to insert airway adjuncts (OPA, NPA)

Decide to use supraglottic device (King LT, Combitube, LMA), ETI, or BMV

Provide positive pressure ventilation with BVM in respiratory distress

Decide whether to attempt intubation in pediatric patient

AW-6

AW-7

Decide whether to attempt intubation in major trauma patient

Decide to use CPAP

AW-8

AW-9

C-1

Decide to perform chest needle decompression

C-2

How to clear obstructed airway (Heimlich manoeuvre, suction, forceps)

C-3

Start CPR

C-4

Begin chest compressions on decompensated child (shock)

Remind/correct chest compressor on CPR quality; have chest compressors switch

Decision to defibrillate

Analyze cardiac rhythm (3- or 4-lead strip)

Interpreting 12-lead ECG

C-6

C-7

Decide on electrical cardioversion or medications for SVT

AW-10 Decide how to confirm intubation

AW-11 Decide to extubate if unsure of placement

AW-12 Failed attempt at intubation; try again for ETI or switch to supraglottic device or BVM

AW-13 Decide whether to perform cricothyrotomy

S-4 Decide most appropriate destination (trauma, heart, stroke centre, community ED, other)

$\mathrm{ASA}=$ acetylisalicylic acid; $\mathrm{BMV}=$ bag-mask ventilation; $\mathrm{CPAP}=$ continuous positive airway pressure $\mathrm{CPR}=$ cardiopulmonary resuscitation; ECG = electrocardiogram; ED = emergency department; ETI = endotracheal intubation; $L M A$ = laryngeal mask airway; $L T=$ laryngeal tube; NPA = nasopharyngeal airway; OPA = oropharyngeal airway; STEMI = ST elevation myocardial infarction; SVT = supraventricular tachycardia; TNK = tenecteplase. 
participated were all advanced care paramedics with considerable EMS experience, so it is possible that the same level of agreement may not be found between all paramedics and medical directors. Reasons why paramedics and medical directors scored these decisions differently were not explored further in this study. An important future study would be to evaluate why paramedics and medical directors feel that different decisions are more important for outcome and safety.

The consensus decisions were plotted onto an emergency call process map. This representation of the processes and decisions involved in a typical call allows one to identify areas of high decision density and determine the point of the call susceptible to near misses, adverse events, and errors. It is apparent from this process map that most of the decisions are consolidated around the on-scene treatment process of the call. This is also the period of a typical emergency call when paramedics deal with uncontrolled settings (outside the ambulance) and are likely to have the least amount of clinical support (e.g., when a paramedic crew arrives on scene and then calls for another crew to give assistance). Although not all of the decisions on the map happen during each emergency call, the map is valuable for increasing awareness of when paramedics are likely to be inundated with many decisions of high risk for lapses in patient safety or outcome. Situations of high decision density are susceptible to provider error. ${ }^{15}$ It should not be misconstrued that this map is an attempt to plot the thinking process that occurs in a paramedic's mind (consciously or subconsciously) as decision making is never a linear process. However, events that occur during an emergency ambulance call are generally predictable, and in most instances, an emergency call is a linear process through time.

This study has consequences for future research on paramedic CDM. Process mapping of specific interventions is valuable for determining the complexities and potential sources of error. ${ }^{16}$ This Delphi study has provided methodological direction for similar studies on interventions known to be of high importance to clinical outcome or patient safety. For example, a similar Delphi study with process mapping could be conducted to analyze paramedic CDM during management of ST segment elevation myocardial infarction patients.

\section{LIMITATIONS}

The results of this study should be considered along with the methodological limitations of a Delphi study. ${ }^{17}$ The decisions found to be important may have differed if the panel was entirely made up of paramedics or medical directors rather than a mix of these groups. Only opinions submitted by panel members were scored, so some important decisions may be missing from this collection. The study was terminated at four rounds, regardless of the number of decisions in which consensus was achieved, to minimize sample fatigue and decreasing response rates. Potentially, additional decisions would have been found to be important if the panel members had the opportunity to review their scores and the panel scores one more time. The Delphi technique calls for panel members to be given the opportunity to rescore items after viewing the panel mean score and their individual previous score for each item. Viewing the group mean may have caused some panel members to score items closer to the group mean, whereas others may have inflated their score to a more extreme value to contradict the group mean.

Decisions were categorized based on the judgment of one of the authors. A post hoc analysis was conducted by the other two authors to check for bias. The authors had good agreement on the classification of the decisions, but the rigour of this process would have been improved with independent analysis by two authors, with third-party adjudication.

The decisions selected as most important for patient safety and clinical outcome were determined by consensus and are not verified by actual patient outcomes or safety data.

The authors reviewed relevant literature and consulted their own knowledge and experience to develop the phases of the process map. The researchers believe that the phases are a good representation of how emergency calls occur in most jurisdictions most of the time. The phases are not the result of empirical research; however, this is another potentially valuable research question.

Finally, and most importantly, the present study took the nominal responses of the Delphi panel at face value to determine a set of decisions paramedics are likely to make during a high-acuity emergency call that are important. The results of this study could be enriched with triangulation with qualitative methods to 
learn more about why the panel felt that the decisions were important, what the process map means to them, and why the paramedics and medical directors scored some decisions differently.

\section{CONCLUSION}

In a Delphi study of CDM by paramedics during highacuity emergency calls, consensus was reached on 42 decisions in six categories. The phase of an emergency call found to have the highest density of important decisions was the on-scene treatment phase. These findings should be a focus of paramedic training, continuing education, and continuous quality improvement in an effort to minimize clinical errors and improve EMS patient safety and clinical outcomes.

Competing interests: Funding was provided by a Canadian Patient Safety Institute Studentship Grant, 2009-2011.

\section{REFERENCES}

1. Croskerry P, Sinclair D. Emergency medicine: a practice prone to error? CFEM 2001;3:271-6.

2. O'Connor RE, Slovis CM, Hunt RC, et al. Eliminating errors in emergency medical services: realities and recommendations. Prehosp Emerg Care 2002;6:107-13, doi:10.1080/ 10903120290938913.

3. Wang HE, Lave JR, Sirio CA, et al. Paramedic intubation errors: isolated events or symptoms of larger problems? Health Aff 2006;25:501-9, doi:10.1377/hlthaff.25.2.501.

4. Hobgood C, Xie J, Weiner B, et al. Error identification, disclosure, and reporting: practice patterns of three emergency medicine provider types. Acad Emerg Med 2004;11:196-9.

5. Wang HE, Katz SH. Cognitive control and prehospital endotracheal intubation. Prehosp Emerg Care 2007;11:234-9, doi: $10.1080 / 10903120701204987$.
6. Fairbanks RJ, Crittenden CN, O'Gara KG, et al. Emergency medical services provider perceptions of the nature of adverse events and near misses in out-of-hospital care: an ethnographic view. Acad Emerg Med 2008;15:633-40, doi:10.1111/j.1553-2712.2008.00147.x.

7. Atack L, Maher J. Emergency medical and health providers' perceptions of key issues in prehospital patient safety. Prehosp Emerg Care 2010;14:95-102, doi:10.3109/ 10903120903349887.

8. Online survey service. Opinio, 2007. Available at: http:// its.dal.ca/services/other_services/online_surveys/ (accessed April 1, 2007).

9. Goodman CM. The Delphi technique: a critique. 7 Adv Nurs 1987;12:729-34, doi:10.1111/j.1365-2648.1987.tb01376.x.

10. Hasson F, Keeney S, McKenna H. Research guidelines for the Delphi survey technique. 7 Adv Nurs 2000;32:1008-15.

11. Williams PL, Webb C. The Delphi technique: a methodological discussion. 7 Adv Nurs 1994;19:180-6, doi:10.1111/ j.1365-2648.1994.tb01066.x.

12. Klotz L. The impact of process mapping on transparency. Int 7 Product Perform Mgt 2008;57:623, doi:10.1108/ 17410400810916053

13. Jensen JL, Croskerry P, Travers AH. Paramedic clinical decision making during high acuity emergency calls: design and methodology of a Delphi study. BMC Emerg Med 2009; 9:17, doi:10.1186/1471-227X-9-17.

14. Kassirer JP, Kopelman RL. Learning clinical reasoning from examples. Hosp Pract 1989;24:27, 32-4, 44-5.

15. Croskerry P, Cosby KS, Schenkel SM, Wears RL, editors. Patient safety in emergency medicine. Philadelphia: Wolters Kluwer Health/Lippincott Williams \& Wilkins; 2009.

16. Blanchard I, Clayden D, Vogelaar G, et al. Adult prehospital rapid-sequence intubation process map: a clinical management tool. Prehosp Emerg Care 2009;13:126, doi:10.1080/ 10903120903144973.

17. Crisp J, Pelletier D, Duffield C, et al. The Delphi method? Nurs Res 1997;46:116, doi:10.1097/00006199-19970300000010 . 